ORIGINAL

\title{
Predictive factors associated with the therapeutic response in patients with polymyalgia rheumatica and remitting seronegative symmetrical synovitis with pitting edema syndrome
}

\author{
Kenji Tani ${ }^{1}$, Shingo Kawaminami², Yoshihiro Okura ${ }^{1}$, Ryo Tabata $^{2}$, Shino Yuasa ${ }^{3}$, Yoshinori Nakanishi ${ }^{2}$, \\ Keisuke Kawahito ${ }^{4}$, Keisuke Inaba², Kaori Inaba², Keisuke Kondo ${ }^{5}$, Kazumasa Umetani ${ }^{6}$, Akiko Miyatake ${ }^{7}$, \\ Yoshihiro Suzuki², and Harutaka Yamaguchi²
}

\begin{abstract}
${ }^{1}$ General Medicine and Primary Care, Tokushima University Hospital, Tokushima, Japan, ${ }^{2}$ Department of General Medicine, Institute of Biomedical Sciences, the University of Tokushima Graduate School, Tokushima, Japan ; ${ }^{3}$ Tokushima Prefectural Central Hospital, Tokushima, Japan, ${ }^{4}$ Yoshinogawa Medical Center, Tokushima, Japan, ${ }^{5}$ Ehime Prefectural Central Hospital, Ehime, Japan, ${ }^{6}$ Tokyo Bei Urayasu Ichikawa Medical Center, Chiba, Japan, ${ }^{7}$ Naruto Yamakami Hospital, Tokushima, Japan
\end{abstract}

\begin{abstract}
Polymyalgia rheumatica (PMR) and remitting seronegative symmetrical synovitis with pitting edema (RS3PE) syndrome are common inflammatory rheumatic diseases in the elderly. In this study, we investigate predictive factors which correspond to subsequent disease control of PMR and RS3PE syndrome. Twenty four patients, which contained 18 PMR and 6 RS3PE syndrome, were treated with initial dosages of 10-20 mg per day oral prednisolone, and the dosage of prednisolone was then tapered. Significantly higher initial CRP was observed in patients with poor disease control than in those with good disease control afterwards. The number of patients with negative CRP after 4 weeks was significantly more in patients with good disease control after 1 year than in those with poor disease control. Patients were shown to be in good disease control status after 1 year when CRP after 4 weeks became negative even if they had initial high CRP. Our study clarify that to make CRP negative after 4 weeks is associated with subsequent suppression of the disease activity and with decreased dosages of corticosteroids. J. Med. Invest. 66 : 112-118, February, 2019
\end{abstract}

Keywords : PMR, RS3PE syndrome, C-reactive protein, prednisolone, relapse

\section{INTRODUCTION}

Polymyalgia rheumatica (PMR), was first described by Barber in 1957 , is a common inflammatory rheumatic disease (1). It usually has its onset in the elderly individuals aged over 50 , and is characterized by pain and morning stiffness in the neck, shoulder, and pelvicgirdle with elevated acute phase reactants such as $\mathrm{C}$-reactive protein (CRP) (2). It has been known to respond well to low dosages of corticosteroids.

Remitting seronegative symmetrical synovitis with pitting edema (RS3PE) syndrome, which was described in 1985 by McCarty et $a l$. as an original subgroup of seronegative rheumatoid arthritis, is also an elderly onset inflammatory rheumatic disease (3). It occurs usually in people older than 60 . The onset of the disease is sudden and it is characterized by a symmetrical polyarthritis associated with pitting edema of the extremities of the upper and lower limbs, elevated acute phase reactants and negative rheumatoid factor (4).

Corticosteroids are used as a standard therapy in both PMR and RS3PE syndrome $(4,5)$. Typically, the starting dosages are 10-20 $\mathrm{mg}$ per day of prednisolone, and gradually tailor tapering. Since the therapy usually results in rapid resolution of symptoms $(6,7)$, lack of response may indicate an incorrect diagnosis. However, approximately one-third of patients have been shown to experience disease relapse during reducing the drug (8). Thus, there is

Received for publication May 8, 2018 ; accepted November 20, 2018.

Address correspondence and reprint requests to Kenji Tani, M.D., General Medicine and Primary Care, Tokushima University Hospital, 50 Kuramoto-cho 2, Tokushima 770-8503, Japan and Fax : +81-88-633-9687. considerable heterogeneity in their clinical courses, steroid requirements for suppression of disease activities, and the likelihood of relapse. Accordingly, it is important to clarify factors at onset and at early time of the therapy to distinguish patients who develop a subsequent relapse from those who do not. However, predictive factors of subsequent disease prognosis of PMR and RS3PE syndrome have not been well clarified.

The aim of this study is to evaluate predictive factors which correspond to subsequent disease control and relapse of PMR and RS3PE syndrome.

\section{PATIENTS AND METHODS}

\section{Patients}

We retrospectively identified the medical records of 26 patients with PMR and RS3PE syndrome visiting regularly Specialty Outpatient Clinic for Collagen Vascular Diseases at Kaifu prefectural hospital and Toyo hospital as an outpatient between Jan in 2015 and Jul in 2017 over 2 years after the treatment were included in this study. PMR was diagnosed according to the Bird's criteria ; (a) bilateral shoulder pain or stiffness, or both, (b) onset of illness within 2 weeks, (c) initial ESR $>40 \mathrm{~mm} / \mathrm{h}$, (d) duration of stiffness $>1 \mathrm{~h}$, (e) age 65 years or older, (f) depression or weight loss, or both, and (g) bilateral upper arm tenderness (9). If any three or more of the seven criteria, a diagnosis of probable PMR was made. None of the patients complicated giant cell arteritis (GCA) during the follow-up in this study. RS3PE syndrome was diagnosed if patients were older than 50 and satisfied the following diagnostic criteria ; symmetrical polyarthritis, pitting edema of the 
bilateral hands and foots, serological absence of rheumatoid factor, and a fast response to steroid therapy (10). In this study, two male patients were complicated by malignant diseases, hepatoma and lung cancer, after the diagnosis with RS3PE syndrome. Since two patients who complicated with malignant diseases (hepatoma and lung cancer) were excluded from this study because malignant diseases might affect the clinical course of PMR and RS3PE syndrome, 24 patients were included in this study.

After the diagnosis, all patients were treated with initial dosages of 10-20 mg per day oral prednisolone according to 2015 Recommendations for the management of PMR (11). Clinical assessments included symptoms and the measurement of serum CRP by standard laboratory methods because elevated levels of CRP are common in patients with PMR and RS3PE syndrome (12). Visits were scheduled every 2 to 4 weeks, and at each visit the dosage of prednisolone was tapered by a tapering schedule of 1 to $2.5 \mathrm{mg}$ reduction when no specific symptoms were complained and CRP was normal or nearly normal. Prednisolone free remission was defined as the absence of clinical symptoms and normal levels of CRP with discontinuation of any drugs which control the diseases including corticosteroids. A relapse was defined as an aggravation or reappearance of clinical symptoms associated with an elevated $\mathrm{CRP}$. If the disease activity relapsed after dose tapering, the prednisolone was increased to dosages related to the disease requiring.

This study was conducted in accordance with the Declaration of Helsinki 1975, as revised in 2008 and approved by the Tokushima University Hospital Research Ethics Board.

\section{Statistical analysis}

Comparison between groups was made using Mann-Whitney U test for continuous variables and Pearson's chi-squared test for categorical variables. Data were mainly presented as median and $\left(25^{\text {th }}-75^{\text {th }}\right.$ quarter $)$, mean \pm standard deviation (SD), count and (percentage), or odds ratio (OR) and $95 \%$ confidence interval (CI). The results were regarded as significant when $\mathrm{p}$ value was $<0.05$. All statistical analyses were performed using IBM SPSS statistics version 24 software (Chicago, IL, USA).

\section{RESULTS \\ Patient characteristics and clinical findings}

Table 1 shows the summary of clinical and laboratory variables. Twenty four patients were included in this study. Eighteen patients were diagnosed as PMR and 6 patients of RS3PE syndrome. Patients consisted of 16 women (67\%) and 8 men (33\%) with median age of 74.5 y.o. (range $62-88$ ). The level of CRP before the treatment (initial CRP) was elevated in all cases (median ; $8.7 \mathrm{mg} / \mathrm{dl}$, range ; 2.9-14.7). All patients were treated with oral prednisolone (median ; $15 \mathrm{mg} /$ day, range ; $10-20$ ). The median duration from onset to treatment start was 8 weeks (range; 1 -52 weeks). The clinical responses during 1 year since the treatment start (till 1 year) and during 2 years since the treatment start (till 2 years) were examined. The level of CRP was decreased 4 weeks after the treatment (median ; $0.65 \mathrm{mg} / \mathrm{dl}$, range ; 0.05-6.08). Prednisolone free remission was seen in a patient (4.2\%) and 4 patients (16.7\%) till 1 year and 2 years, respectively. A relapse was shown in 4 patients (16.7\%) and 7 patients $(29.2 \%)$ till 1 year and 2 years, respectively.

The percentage of women was significantly $(p=0.003)$ more in PMR (83.3\%) than in RS3PE syndrome (16.7\%), but no significance was seen in the other variables such as age, the duration from onset to treatment start, CRP levels, starting doses of prednisolone, duration from initial treatment to negative CRP, or the rate of relapse between PMR and RS3PE syndrome.

\section{The relation of initial CRP levels with disease control}

The level of initial CRP was compared between two groups divided by disease control status of patients who were followed up for 1 year and 2 years after the treatment. The mean dosage of prednisolone after 1 year was $4.2 \pm 2.3$ (median ; 4$) \mathrm{mg} /$ day in patients without relapse. Therefore, patients were divided into two groups according to prednisolone dosages after 1 year; one group consisted of patients treated with less than $5 \mathrm{mg}$ of prednisolone (Good control), the other group of those treated with $5 \mathrm{mg}$ or more of prednisolone (Poor control). Patients who had shown relapse till 1 year were included in Poor control. No patients who had shown relapse till 1 year received less than $5 \mathrm{mg}$ of prednisolone after 1 year. As shown in Fig. 1A, significantly higher initial CRP levels were observed in Poor control than in Good control. Significantly higher initial CRP was also observed in patients with relapse than in those without relapse till 1 year (Fig. 1B) and till 2

Table 1 Clinical features of patients

\begin{tabular}{lc}
\hline Variables $(\mathrm{n}=24)$ & values \\
\hline PMR/RS3PE syndrome & $18(75 \%) / 6(25 \%)$ \\
Gender, men/women & $8(33 \%) / 16(67 \%)$ \\
Age, years & $74.5(71.3-81.8)$ \\
Initial CRP, mg/dl ; normal range $<0.3$ & $8.7(4.2-10.8)$ \\
Starting dose of prednisolone, mg/day & $15.0(11.3-15.0)$ \\
Duration from onset to treatment start, weeks & $8.0(4.3-15.5)$ \\
CRP after 4 weeks, mg/dl & $0.65(0.11-0.97)$ \\
Duration from initial treatment to negative CRP, weeks & $7.5(3.3-12.8)$ \\
Becoming negative CRP after 4 weeks & $8(33.3 \%)$ \\
Becoming negative CRP after 8 weeks & $13(54.2 \%)$ \\
Prednisolone free remission till 1 year & $1(4.2 \%)$ \\
Prednisolone free remission till 2 years & $4(16.7 \%)$ \\
Relapse till 1 year & $4(16.7 \%)$ \\
Relapse till 2 years & $7(29.2 \%)$ \\
\hline
\end{tabular}

PMR ; polymyalgia rheumatica, RS3PE ; remitting seronegative symmetrical synovitis with pitting edema. Twenty five patients were included in this study. Data were presented as counts and (percentage), or median and (interquartile range). 


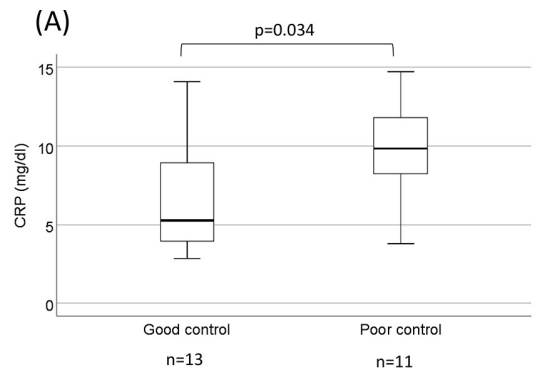

(B)

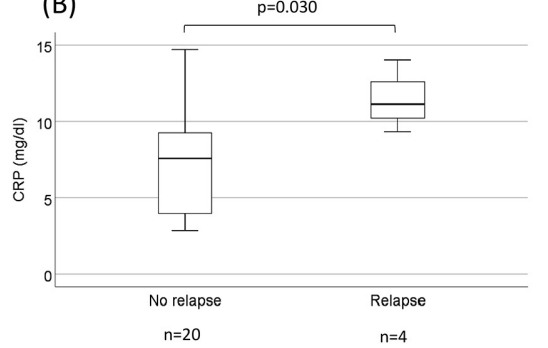

(C)

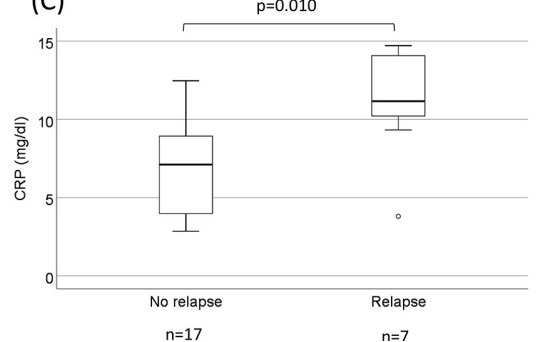

Figure 1. The relation of initial CRP levels with disease control 1 year and 2 years after the treatment. A) Initial CRP levels comparing between patients with Good control and Poor control after 1 year. Patients were divided into two groups according to prednisolone dosages after 1 year ; one group consisted of patients treated with less than $5 \mathrm{mg}$ of prednisolone (Good control), the other group of those treated with $5 \mathrm{mg}$ or more of prednisone (Poor control). Patients who had showed relapse till 1 year were included in Poor control. B) Initial CRP levels comparing between patients with and without relapse after 1 year. C) Initial CRP levels comparing between patients with and without relapse after 2 years.

years (Fig. 1C). Duration from onset to treatment start was not significantly different between patients in Good control and Poor control after 1 year (Fig. 2). Disease difference (PMR or RS3PE syndrome), age, or gender did not affect disease control status after 1 year and 2 years (data not shown).

The relation of duration from the treatment start to becoming CRP negative with disease control

Whether duration from treatment start with prednisolone to becoming CRP negative correspond to the subsequent disease control status was examined. The duration was significantly longer in patients in Poor control after 1 year than in those in Good control after 1 year (Fig. 3A). The duration was also significantly longer in

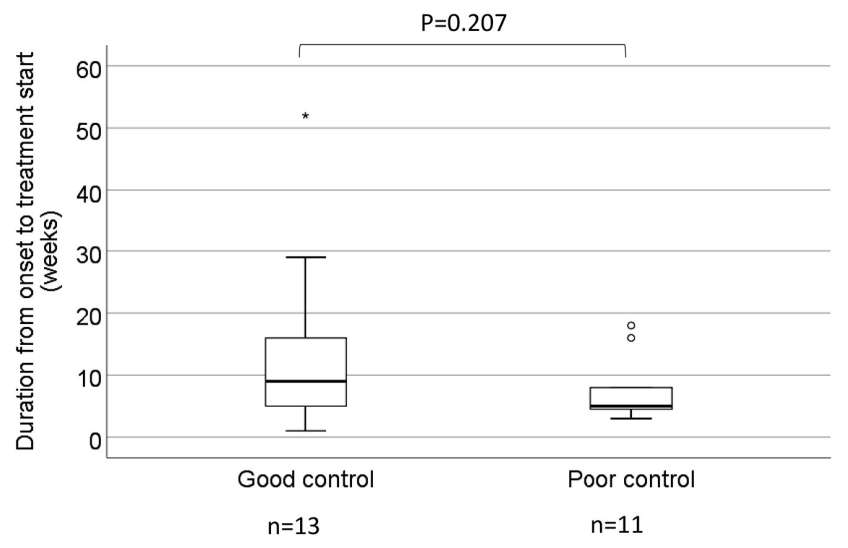

Figure 2. The relation of duration from onset to treatment start with disease control status 1 year after the treatment. Patients were divided into two groups according to prednisolone dosages after 1 year; one group consisted of patients treated with less than $5 \mathrm{mg}$ of prednisolone (Good control), the other group of those treated with $5 \mathrm{mg}$ or more of prednisone (Poor control). Patients who had showed relapse till 1 year were included in Poor control. patients with relapse till 1 year and till 2 years than in those without relapse (Figs. 3B and 3C, respectively). These data suggest that to make CRP negative earlier resulted in good suppression of the disease activity and in decreasing the dosage of prednisolone.

The relation of CRP positivity after 4 weeks with disease control

We next examined the relation of time course of CRP with disease control status. Patients were divided into two groups, High CRP and Low CRP, by the median level of initial CRP $(8.7 \mathrm{mg} / \mathrm{dl})$ followed by comparing CRP positivity after 4 weeks and disease control status after 1 year (Fig. 4). Before the treatment, 12 patients (50\%) were included in High CRP, and 12 (50\%) were in Low CRP. After 4 weeks, 3 patients (25\%) were in Negative CRP group from initial High CRP, but more patients $(n=5,42 \%)$ were in Negative CRP group from initial Low CRP. On the other hand, 1 year after the treatment, all of patients with Negative CRP after 4 weeks were included in Good control in spite of initial CRP levels. These results indicate that patients could be in Good control after 1 year when CRP after 4 weeks was negative even if they had initial High CRP.

Next, the relation of initial CRP, CRP positivity after 4 weeks, and disease control disease status after 1 year was further examined by chi-squared test. As shown in Table 2, initial CRP levels were not associated with CRP positivity after 4 weeks (OR ; $2.14,95 \% \mathrm{CI}$; $0.38-12.2, \mathrm{p}=0.386$ ). On the other hand, CRP positivity after 4 weeks was significantly associated with disease control status after 1 year (OR ; 3.20, 95\%CI ; 1.55-6.62, $\mathrm{p}=0.001)$. As shown in Table 3 , CRP positivity after 8 weeks was also significantly associated with disease control status after 1 year $(\mathrm{OR} ; 24.75,95 \% \mathrm{CI}$; 2.89-212.23, $\mathrm{p}=0.001)$.

The relation between initial CRP level and starting doses of prednisolone

All patients were treated with oral prednisolone after the diagnosis. Initial prescription dosages of prednisolone had been decided by a judgement of a doctor which depended on patient's total disease activity. Six patients were treated with $10 \mathrm{mg} /$ day, 17 patients with $15 \mathrm{mg} /$ day, and a patient with $20 \mathrm{mg} /$ day. Patients 

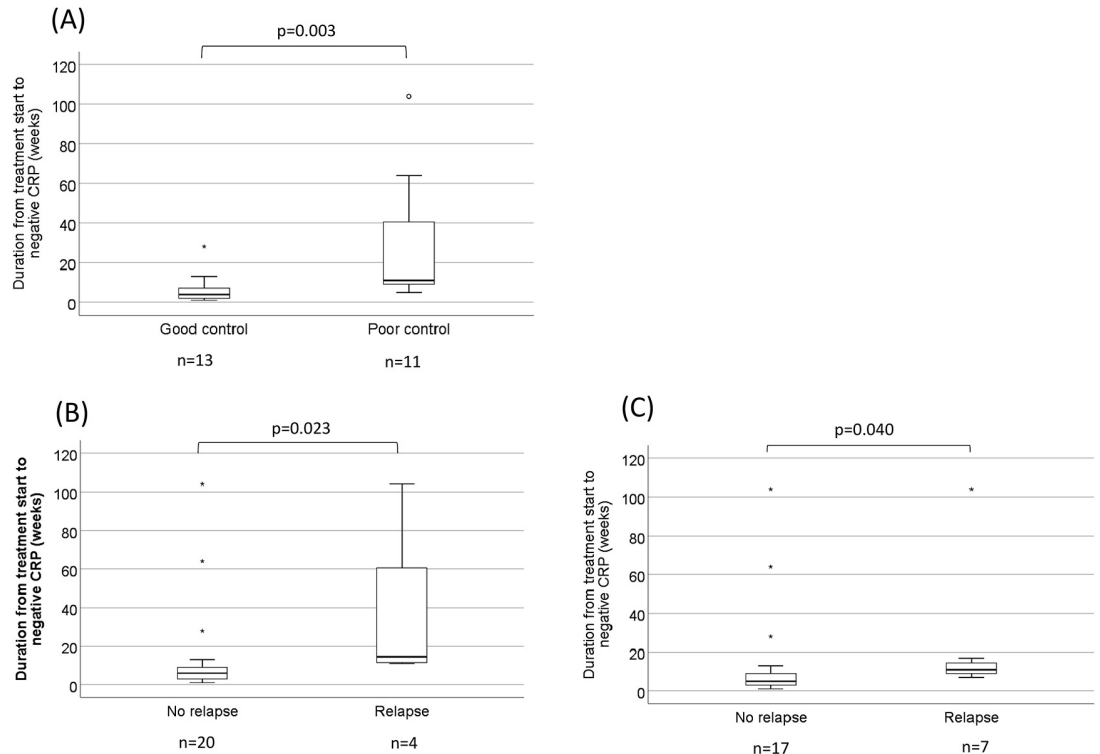

Figure 3. The relation of duration from treatment start to becoming CRP negative with disease control status. A) Comparison of duration from treatment start to becoming CRP negative between patients in Good control and Poor control after 1 year, as described in the legend of Figure 1. B) Comparison of duration from treatment start to becoming CRP negative between patients with relapse and without relapse after 1 year. C) Comparison of duration from treatment start to becoming CRP negative between patients with relapse and without relapse after 2 years.

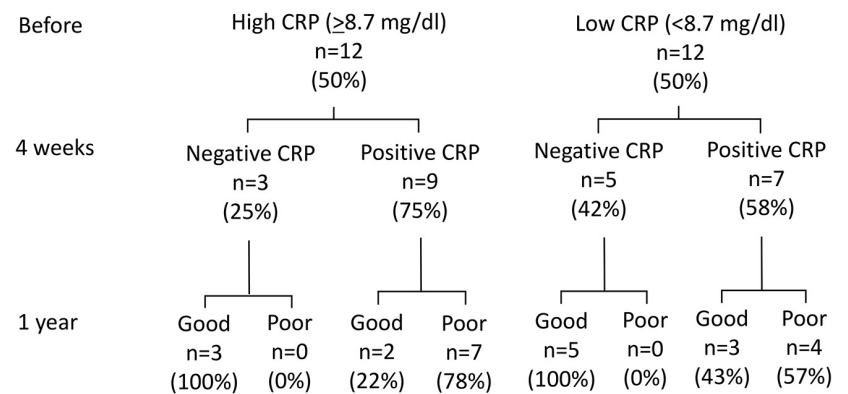

Figure 4. The relation between time course of CRP and disease control status. Patients were divided into two groups by the median level of initial CRP $(8.7 \mathrm{mg} / \mathrm{dl})$. After the treatment, patients were divided into two groups by the positivity of CRP, positive or negative, after 4 weeks and were divided into two groups, Good control and Poor control, in 1 year, as described in the legend of Figure 1. were divided into 2 groups by the starting doses of prednisolone, 10 $\mathrm{mg}$ per day or over $10 \mathrm{mg}$ per day, and then clinical findings were compared between 2 groups. Although the level of initial CRP tended to be higher in $>10 \mathrm{mg}$ group than in $10 \mathrm{mg}$ group, there was no significant difference (Fig. 5), indicating that starting dosage might not be decided only by initial levels of CRP. The starting dose of prednisolone did not affect CRP positivity after 4 weeks or the disease control status after 1 year (data not shown).

\section{DISCUSSION}

This study demonstrates that CRP is a crucial marker to predict the disease control after the treatment with corticosteroids. Patients with high initial CRP showed poor disease control after 1 year and 2 years, and to make CRP negative early resulted in subsequent good control status. Although there have been some reports which dem-

Table 2 The relation among initial CRP, CRP positivity after 4 weeks, and disease control status after 1 year

\begin{tabular}{|c|c|c|c|c|c|c|c|c|}
\hline Initial CRP & n (\%) & $\begin{array}{c}\text { CRP after } 4 \\
\text { weeks }\end{array}$ & $\mathrm{n}(\%)$ & $\begin{array}{l}\text { Control status } \\
\text { after } 1 \text { year }\end{array}$ & n (\%) & OR & $95 \% \mathrm{CI}$ & $P$ value \\
\hline \multirow{2}{*}{ High $(\geq 8.7)$} & \multirow{2}{*}{$12(50)$} & Positive & $9(75)$ & & & \multirow{4}{*}{2.14} & \multirow{4}{*}{$0.38-12.2$} & \multirow{4}{*}{$\mathrm{P}=0.386$} \\
\hline & & Negative & $3(25)$ & & & & & \\
\hline \multirow{6}{*}{ Low $(<8.7)$} & \multirow{6}{*}{$12(50)$} & Positive & $7(58)$ & & & & & \\
\hline & & Negative & $5(42)$ & & & & & \\
\hline & & & & Poor control & $11(69)$ & \multirow{4}{*}{3.20} & \multirow{4}{*}{$1.55-6.62$} & \multirow{4}{*}{$\mathrm{P}=0.001$} \\
\hline & & Positive & $16(67)$ & Good control & $5(31)$ & & & \\
\hline & & \multirow{2}{*}{ Negative } & \multirow{2}{*}{$8(33)$} & Poor control & $0(0)$ & & & \\
\hline & & & & Good control & $8(100)$ & & & \\
\hline
\end{tabular}

Patients were divided into two groups by median value of initial CRP ( $8.7 \mathrm{mg} / \mathrm{dl})$. Four weeks after the treatment, patients were divided into two groups by the positivity of CRP, positive and negative. Patients were divided into two groups according to prednisolone dosages after 1 year ; one group consisted of patients treated with less than $5 \mathrm{mg}$ of prednisolone (Good control), the other group of those treated with $5 \mathrm{mg}$ or more of prednisolone (Poor control). Patients who had showed relapse till 1 year were included in Poor control group. P values were calculated using Pearson's chi-square test. OR; odds ratio, CI ; confidence interval 
Table 3 The relation among initial CRP, CRP positivity after 8 weeks, and disease control status after 1 year

\begin{tabular}{|c|c|c|c|c|c|c|c|c|}
\hline Initial CRP & n (\%) & $\begin{array}{c}\text { CRP after } 8 \\
\text { weeks }\end{array}$ & n (\%) & $\begin{array}{l}\text { Control status } \\
\text { after } 1 \text { year }\end{array}$ & n (\%) & OR & $95 \% \mathrm{CI}$ & $P$ value \\
\hline \multirow{2}{*}{ High $(\geq 8.7)$} & \multirow{2}{*}{$12(50)$} & Positive & $8(67)$ & & & \multirow{4}{*}{6.00} & \multirow{4}{*}{$1.02-35.37$} & \multirow{4}{*}{$\mathrm{P}=0.041$} \\
\hline & & Negative & $4(33)$ & & & & & \\
\hline \multirow{6}{*}{ Low $(<8.7)$} & \multirow{6}{*}{$12(50)$} & Positive & $3(25)$ & & & & & \\
\hline & & Negative & $9(75)$ & & & & & \\
\hline & & Pooiting & $11(16)$ & Poor control & $9(82)$ & \multirow{4}{*}{24.75} & \multirow{4}{*}{$2.89-212.23$} & \multirow{4}{*}{$\mathrm{P}=0.001$} \\
\hline & & Posiuve & $11(46)$ & Good control & $2(18)$ & & & \\
\hline & & \multirow{2}{*}{ Negative } & \multirow{2}{*}{$13(54)$} & Poor control & $2(15)$ & & & \\
\hline & & & & Good control & $11(85)$ & & & \\
\hline
\end{tabular}

Patients were divided into two groups by median value of initial CRP $(8.7 \mathrm{mg} / \mathrm{dl})$. Eight weeks after the treatment, patients were divided into two groups by the positivity of CRP, positive and negative. Patients were divided into two groups according to prednisolone dosages after 1 year ; one group consisted of patients treated with less than $5 \mathrm{mg}$ of prednisolone (Good control), the other group of those treated with $5 \mathrm{mg}$ or more of prednisolone (Poor control). Patients who had showed relapse till 1 year were included in Poor control group. P values were calculated using Pearson's chi-square test. OR; odds ratio, $\mathrm{CI}$; confidence interval

onstrate the relation between initial CRP levels and the subsequent therapeutic responses, discrepancies are present in the reports. PMR patients with an initial CRP $>2.5 \mathrm{mg} / \mathrm{dl}$ have a greater possibility of relapse (2), and high levels of initial CRP are predominantly distributed in patients with RS3PE syndrome whose CRP level after 1 year is $>0.5 \mathrm{mg} / \mathrm{dl}$ (4). On the other hand, there have been reports which demonstrate that initial levels of CRP do not affect the clinical response of PMR $(13,14)$ or RS3PE syndrome (15). The differences are suggested to be due to therapeutic strategies such as the difference in starting dosage and dose tapering speed of corticosteroids.

We found that the positivity of CRP after 4 weeks was a crucial marker of the disease control after 1 year and 2 years. Patients were in good disease control after 1 year when CRP after 4 weeks could become negative even if initial CRP levels were high. This is the first study which focuses on the early response of CRP to the therapy, and indicates that the positivity of CRP after 4 weeks is more crucial predictor of subsequent poor disease control and relapse in PMR and RS3PE syndrome than initial CRP levels. Although CRP positivity after 8 weeks also predicted the disease control status after 1 year, CRP levels after 4 weeks may be more useful as an earlier predictor. There was no significant difference in initial CRP levels among starting dosages of prednisolone. In this

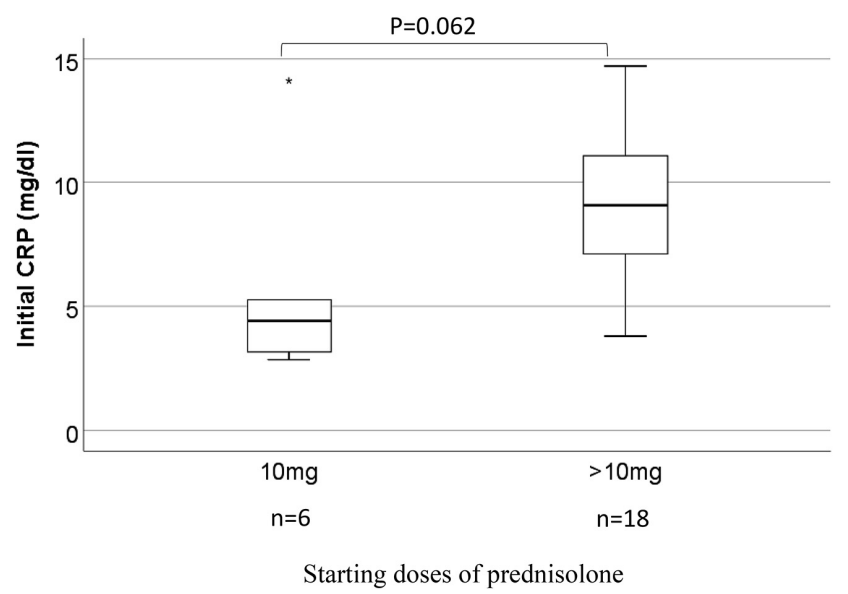

Figure 5. The relation of initial CRP levels with starting doses of prednisolone. Patients were divided into two groups according to starting doses of prednisolone, $10 \mathrm{mg}$ or over $10 \mathrm{mg}$ per day, and initial CRP levels were compared between the two groups. study, most patients (71\%) were treated with same initial dosage (15 mg/day) according to the suggestion by the British Society for Rheumatology (BSR) which recommended a starting dosage of 15 $\mathrm{mg} /$ day of prednisolone for PMR (16). More initial dosages or longer duration of prednisolone may be needed to patients with high level of initial CRP. It is important to select an appropriate starting dosage and tapering speed of prednisolone for each patient. Less starting dosages of prednisolone and fast tapering speed may result in subsequent relapse. Conversely, over dosages and slow tapering speed may induce various adverse events such as infection and osteoporosis especially in elderly patients. On the other hand, some previous reports showed that clinical relapse is not statistically linked to the initial dosages of corticosteroids $(2,17,18)$. A previous report showed that the factor predicting a good response to the therapy of PMR is low body weight but not the disease severity (19). Further studies are needed to determine how an appropriate starting dosage and duration of prednisolone for each patient with PMR and RS3PE syndrome should be determined.

In this study, no significant difference was seen between duration from the onset to treatment start and subsequent disease control status, indicating that the delay in treatment start may not affect the subsequent therapeutic response and prognosis. The result was not in agreement with a previous report that the duration of symptoms before diagnosis is longer in PMR patients with relapse than in those without relapse (20). The reason of the difference is not clear because there is no difference in clinical features such as the mean duration of symptoms before diagnosis and starting prednisolone dosages between the report and this study. On the other hand, in this study, there was no significant difference between men and women in the disease control of patients with PMR or RS3PE syndrome. Origuchi et al. reported that male gender is predominantly distributed in patients with RS3PE syndrome whose response to corticosteroids is poor (4). Other previous reports showed that there are more female in relapse group of patients with PMR $(2,21,22)$. Mackie et al. (23) showed that female gender increases the risk of late GCA that needs high dosages of corticosteroids to prevent severe complications such as blindness and cerebral infarction (24-26). In this study, none of the patients complicated GCA during the follow-up. Thus, the rate of complications such as GCA is possible to contribute to the difference in the response to corticosteroids observed in gender.

We measured CRP levels as a marker of disease activity of PMR and RS3PE syndrome in this study. The erythrocyte sedimentation rate (ESR) has been known to be useful to examine the activity of these diseases as well as CRP $(2,6)$. However, we selected CRP in this study because ESR might be influenced by various factors 
such as anemia.

In this study, we examined the predictive factors associated with the therapeutic response in patients together with PMR and RS3PE syndrome. PMR and RS3PE syndrome are common diseases in the elderly, and conventionally treated with long-term oral corticosteroids $(2,4)$. PMR and RS3PE syndrome have various common characteristics; both are common rheumatic disorders in the elderly, and show suddenly occurred clinical symptoms, elevation of acute phase reactants such as CRP, negative rheumatoid factor, and effective low dosages of corticosteroids. Synovitis of peripheral joints, which are characterized by RS3PE syndrome, is also present in up to $25 \%$ of patients with PMR (27-30). The rate of associated malignancy was reported not to be different between RS3PE syndrome and PMR (31) though it has been known to be characterized by RS3PE syndrome $(3,4)$. This study also showed that there were no significant differences between PMR and RS3PE syndrome in various clinical features except gender. Taken together, in this study, clinical factors predicting the disease control were examined together in patients with PMR and RS3PE syndrome.

Many reports have shown the therapeutic responses after the treatment with corticosteroid in patients with PMR and RS3PE syndrome $(2,4,18)$ Previous reports showed that $52-56 \%$ of patients have a complete response to corticosteroid therapy $(8,32,33)$. An overall steroid cessation rate in patients with PMR is only $2.5 \%$ at 1 year (2), and $24 \%$ of patients with PMR is able to stop corticosteroid treatment after 2 years (18). Origuchi et al. showed that $82.9 \%$ of patients with RS3PE syndrome are still receiving corticosteroids 1 year after the treatment and $58.5 \%$ of the patients are still receiving over $5 \mathrm{mg}$ /day prednisolone (4). This study showed that $4.2 \%$ and $16.7 \%$ of patients were in prednisolone-free remission after 1 year and 2 years, respectively, and the mean dosage of prednisolone without relapse was $4.2 \mathrm{mg}$ /day after 1 year. Thus, results about therapeutic response in this study were consistent with previous reports.

\section{CONCLUSION}

In this study, we demonstrate that earlier negativity of CRP by the treatment may be important to aim low disease activity and the prevention of relapse of PMR and RS3PE syndrome. However, our study is limited by the fact that it is a retrospective study performed in two hospitals. Future prospective studies are needed to conform our findings. A clinical study to determine an appropriate starting dosage and declining speed of corticosteroids measuring various clinical data is now under investigation in our laboratory.

\section{CONFLICT OF INTEREST}

None of the authors have any conflicts of interest to declare.

\section{ACKNOWLEDGEMENTS}

The authors thank Ms. Yayoi Tagawa for her valuable secretarial support.

\section{REFERENCES}

1. Barber HS : Myalgic syndrome with constitutional effects ; polymyalgia rheumatica. Ann Rheum Dis 16 : 230-237, 1957

2. Lee JH, Choi ST, Kim JS, Yoon BY, Kwok SK, Kim HS, Kim YS, Song JS, Lee SH, Kim HR : Clinical characteristics and prognostic factors for relapse in patients with polymyalgia rheumatica (PMR). Rheumatol Int 33 : 1475-1480, 2013
3. McCarty DJ, O’Duffy JD, Pearson L, Hunter JB : Remitting seronegative symmetrical synovitis with pitting edema. RS3 PE syndrome. JAMA 254 : 2763-2767, 1985

4. Origuchi T, Arima K, Umeda M, Kawashiri SY, Tamai M, Nakamura H, Tsukada T, Miyashita T, Iwanaga N, Izumi Y, Furuyama M, Tanaka F, Kawabe Y, Aramaki T, Ueki Y, Eguchi K, Fukuda T, Kawakami A : Clinical outcomes in the first year of remitting seronegative symmetrical synovitis with pitting edema (RS3PE) syndrome. Mod Rheumatol 27 : 150 154, 2017

5. Schirmer M, Dejaco C, Dasgupta B, Matteson EL : Polymyalgia rheumatica : strategies for efficient practice and quality assurance. Rheumatol Int $35:$ 1781-1789, 2015

6. Okumura T, Tanno S, Ohhira M, Nozu T : The rate of polymyalgia rheumatica (PMR) and remitting seronegative symmetrical synovitis with pitting edema (RS3PE) syndrome in a clinic where primary care physicians are working in Japan. Rheumatol Int 32 : 1695-1699, 2012

7. Origuchi T, Arima K, Kawashiri SY, Tamai M, Yamasaki S, Nakamura H, Tsukada T, Aramaki T, Furuyama M, Miyashita T, Kawabe Y, Iwanaga N, Terada K, Ueki Y, Fukuda T, Eguchi K, Kawakami A : High serum matrix metalloproteinase 3 is characteristic of patients with paraneoplastic remitting seronegative symmetrical synovitis with pitting edema syndrome. Mod Rheumatol 22 : 584-588, 2012

8. Hutchings A, Hollywood J, Lamping DL, Pease CT, Chakravarty K, Silverman B, Choy EH, Scott DG, Hazleman BL, Bourke B, Gendi N, Dasgupta B : Clinical outcomes, quality of life, and diagnostic uncertainty in the first year of polymyalgia rheumatica. Arthritis Rheum 57 : 803-809, 2007

9. Bird HA, Esselinckx W, Dixon AS, Mowat AG, Wood PH : An evaluation of criteria for polymyalgia rheumatica. Ann Rheum Dis 38 : 434-439, 1979

10. Olive A, del Blanco J, Pons M, Vaquero M, Tena X : The clinical spectrum of remitting seronegative symmetrical synovitis with pitting edema. The Catalan Group for the Study of RS3PE. J Rheumatol 24 : 333-336, 1997

11. Dejaco C, Singh YP, Perel P, Hutchings A, Camellino D, Mackie S, Abril A, Bachta A, Balint P, Barraclough K, Bianconi L, Buttgereit F, Carsons S, Ching D, Cid M, Cimmino M, Diamantopoulos A, Docken W, Duftner C, Fashanu B, Gilbert K, Hildreth P, Hollywood J, Jayne D, Lima M, Maharaj A, Mallen C, Martinez-Taboada V, Maz M, Merry S, Miller J, Mori S, Neill L, Nordborg E, Nott J, Padbury H, Pease C, Salvarani C, Schirmer M, Schmidt W, Spiera R, Tronnier D, Wagner A, Whitlock M, Matteson EL, Dasgupta B : European League Against Rheumatism ; American College of Rheumatology. 2015 Recommendations for the management of polymyalgia rheumatica : a European League Against Rheumatism/ American College of Rheumatology collaborative initiative. Ann Rheum Dis 74 : 1799-1807, 2015

12. Dejaco C, Duftner C, Cimmino MA, Dasgupta B, Salvarani C, Crowson CS, Maradit-Kremers H, Hutchings A, Matteson EL, Schirmer M : Definition of remission and relapse in polymyalgia rheumatica : data from a literature search compared with a Delphi-based expert consensus. Ann Rheum Dis 70 : 447-453, 2011

13. Cleuziou C, Binard A, De Bandt M, Berthelot JM, Saraux A : Contribution of the polymyalgia rheumatica activity score to glucocorticoid dosage adjustment in everyday practice. J Rheumatol 39 : 310-313, 2012

14. Cimmino MA, Parodi M, Montecucco C, Caporali R: The correct prednisone starting dose in polymyalgia rheumatica is related to body weight but not to disease severity. BMC Musculoskelet Disord 12 : 94-98, 2011

15. Kimura M, Tokuda Y, Oshiawa H, Yoshida K, Utsunomiya M, 
Kobayashi $\mathrm{T}$ : Clinical characteristics of patients with remitting seronegative symmetrical synovitis with pitting edema compared to patients with pure polymyalgia rheumatica. J Rheumatol 39 : 148-153, 2012

16. Dasgupta B, Borg FA, Hassan N, Barraclough K, Bourke B, Fulcher J : BSR and BHPR Standards, Guidelines and Audit Working Group. BSR and BHPR guidelines for the management of polymyalgia rheumatica. Rheumatology (Oxford) 49 : 186-90, 2010

17. Ornetti P, Guillibert-Karras C, Garrot JF, Gros F, Gérard N, Julien L, Pascaud F, Peere T, Petit-Perrin M, Piroth C, Tavernier C, Maillefert JF : Study of professional practices among rheumatologists in Burgundy. Initial corticotherapy in polymyalgia rheumatica. Clin Rheumatol $30: 51-56,2011$

18. Kyle V, Hazleman BL: The clinical and laboratory course of polymyalgia rheumatica/giant cell arteritis after the first two months of treatment. Ann Rheum Dis 52 : 847-850, 1993

19. Cimmino MA, Parodi M, Montecucco C, Caporali R: The correct prednisone starting dose in polymyalgia rheumatic is related to body weight but not to disease severity. BMC Musculoskeletal Disorders 12 : 94-99, 2011

20. Salvarani C, Cantini F, Niccoli L, Macchioni P, Consonni D, Bajocchi G : Acute-phase reactants and the risk of relapse/ recurrence in polymyalgia rheumatica : a prospective followup study. Arthritis Rheum $53: 33-38,2005$

21. Cimmino MA, Parodi M, Caporali R, Montecucco C: Is the course of steroid-treated polymyalgia rheumatica more severe in women? Ann N Y Acad Sci 1069 : 315-321, 2006

22. Narvaez J, Nolla-Sole JM, Clavaguera MT, Valverde-Garcia J, Roig-Escofet D : Longterm therapy in polymyalgia rheumatica : effect of coexistent temporal arteritis. J Rheumatol 26 : 19451952, 1999

23. Mackie SL, Hensor EM, Haugeberg G, Bhakta B, Pease CT : Can the prognosis of polymyalgia rheumatica be predicted at disease onset? Results from a 5-year prospective study. Rheumatology (Oxford) 49:716-722, 2010

24. Jones JG, Hazleman BL : Prognosis and management of polymyalgia rheumatica. Ann Rheum Dis $40: 1-5,1981$

25. Dejaco C, Brouwer E, Mason JC, Buttgereit F, Matteson EL, Dasgupta B : Giant cell arteritis and polymyalgia rheumatica : current challenges and opportunities. Nat Rev Rheumatol 13 : 578-592, 2017

26. Buttgereit F, Dejaco C, Matteson EL, Dasgupta B : Polymyalgia
Rheumatica and Giant Cell Arteritis : A Systematic Review. JAMA 315 : 2442-2458, 2016

27. Gonzalez-Gay MA, Agudo M, Martinez-Dubois C, Pompei O, Blanco R: Medical management of polymyalgia rheumatica. Expert Opin Pharmacother 11: 1077-1087, 2010

28. Dasgupta B, Salvarani C, Schirmer M, Crowson CS, MaraditKremers H, Hutchings A, Matteson EL: Developing classification criteria for polymyalgia rheumatica : comparison of views from an expert panel and wider survey. J Rheumatol 35 : 270 277, 2008

29. Salvarani C, Cantini F, Macchioni P, Olivieri I, Niccoli L, Padula A, Boiardi L : Distal musculoskeletal manifestations in polymyalgia rheumatica : A prospective follow up study. Arthritis Rheum $41: 1221-1226,1998$

30. Yang DH, Chang DM, Lai JH, Huang GS, Chang WC, Hou TY : Remitting seronegative symmetrical synovitis with pitting edema following acute intracranial hemorrhage. Rheumatol Int 31 : 101-104, 2011

31. Li H, Altman RD, Yao Q : RS3PE : Clinical and research development. Curr Rheumatol Rep 17 : 49-55, 2015

32. Matteson EL, Maradit-Kremers H, Cimmino MA, Schmidt WA, Schirmer M, Salvarani C, Bachta A, Dejaco C, Duftner C, Slott Jensen H, Poór G, Kaposi NP, Mandl P, Balint PV, Schmidt Z, Iagnocco A, Cantini F, Nannini C, Macchioni P, Pipitone N, Del Amo M, Espígol-Frigolé G, Cid MC, MartínezTaboada VM, Nordborg E, Direskeneli H, Aydin SZ, Ahmed K, Hazelman B, Pease C, Wakefield RJ, Luqmani R, Abril A, Marcus R, Gonter NJ, Maz M, Crowson CS, Dasgupta B : Patient-reported outcomes in polymyalgia rheumatica. J Rheumatol 39 : 795-803, 2012

33. Dasgupta B, Cimmino MA, Maradit-Kremers H, Schmidt WA, Schirmer M, Salvarani C, Bachta A, Dejaco C, Duftner C, Jensen HS, Duhaut P, Poór G, Kaposi NP, Mandl P, Balint PV, Schmidt Z, Iagnocco A, Nannini C, Cantini F, Macchioni $P$, Pipitone N, Del Amo M,Espígol-Frigolé G, Cid MC, MartínezTaboada VM, Nordborg E, Direskeneli H, Aydin SZ, Ahmed K, Hazleman B, Silverman B, Pease C, Wakefield RJ, Luqmani R, Abril A, Michet CJ, Marcus R, Gonter NJ, Maz M, Carter RE, Crowson CS, Matteson EL : 2012 provisional classification criteria for polymyalgia rheumatica : a European League Against Rheumatism/American College of Rheumatology collaborative initiative. Ann Rheum Dis 71 : 484-492, 2012 